\title{
ÜBERSICHTSTAFEL DER GRIMM'SCHEN MÄRCHEN
}

(Die folgende Tabelle gibt die einzelnen Grimmschen Märchen, die Stelle ihres ersten Erscheinens, die Behandlungsstelle bei Bolte-Polivka, die betr. Motivnummer vonAarne-Thompson, die Nummer, unter der v. d. Leyens historische Anordnung das betr. Märchen bringt und schließlich unser Stichwort in synoptischer Zusammenstellung.)

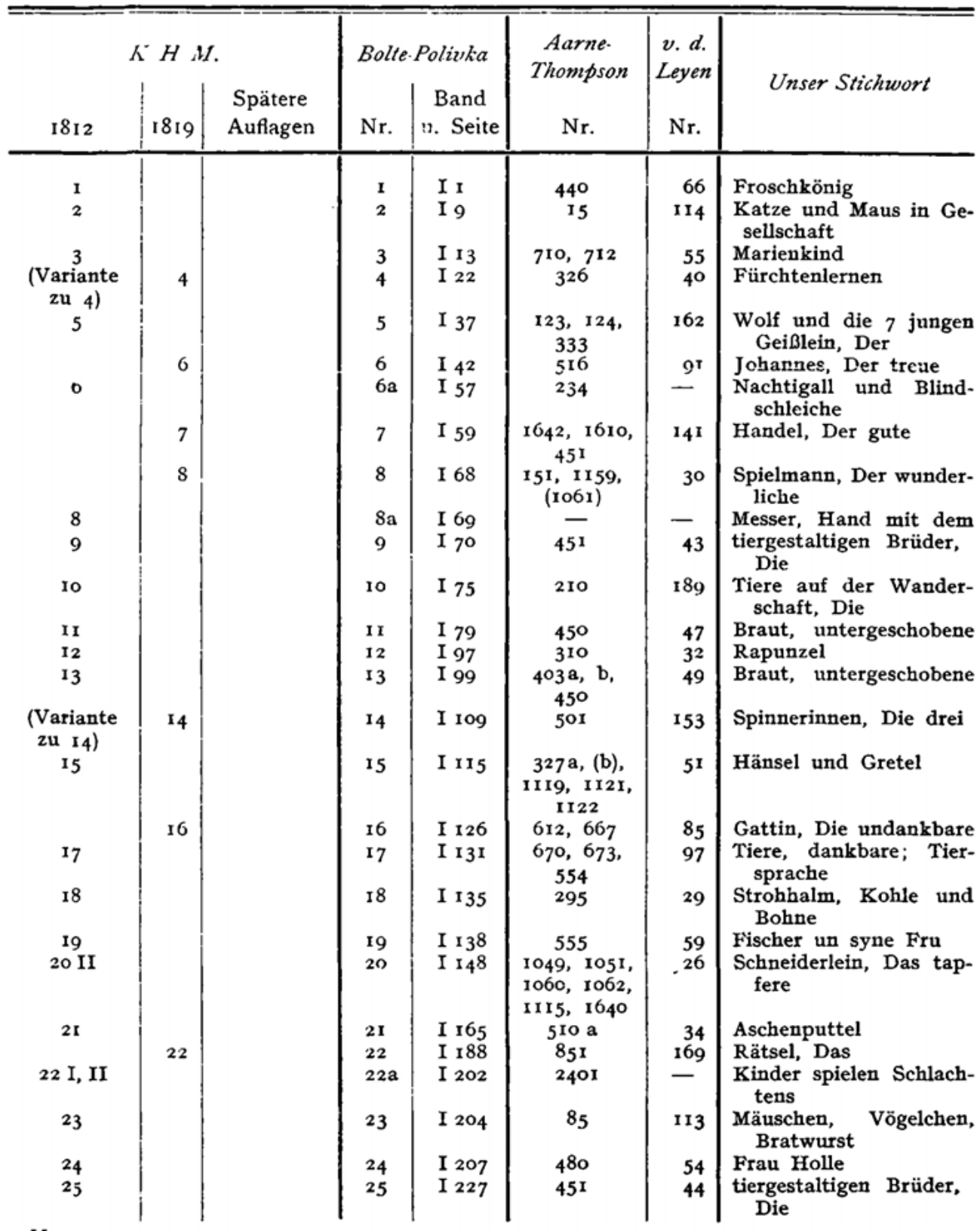

II Märchen-I,cxikon 2. L. 


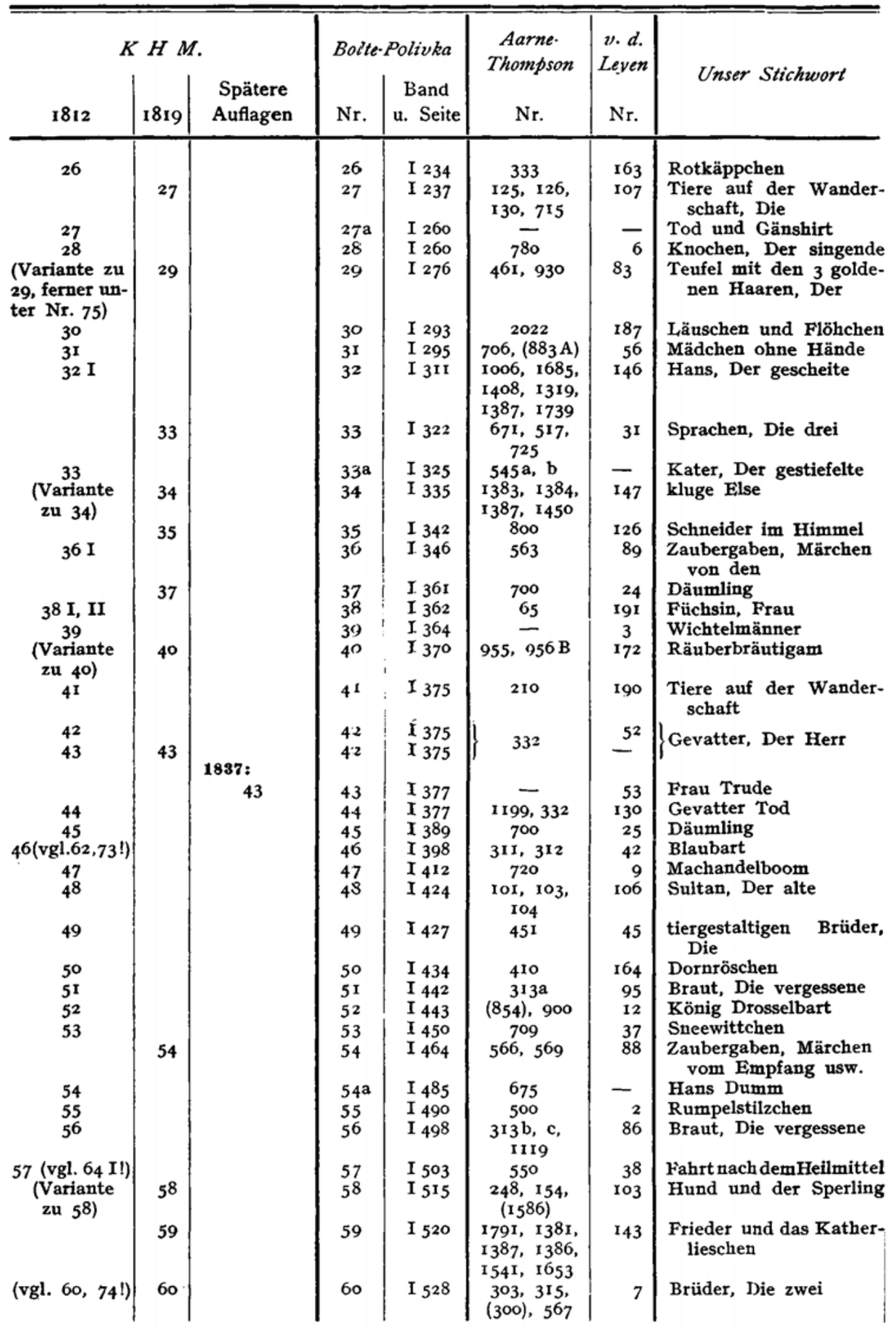




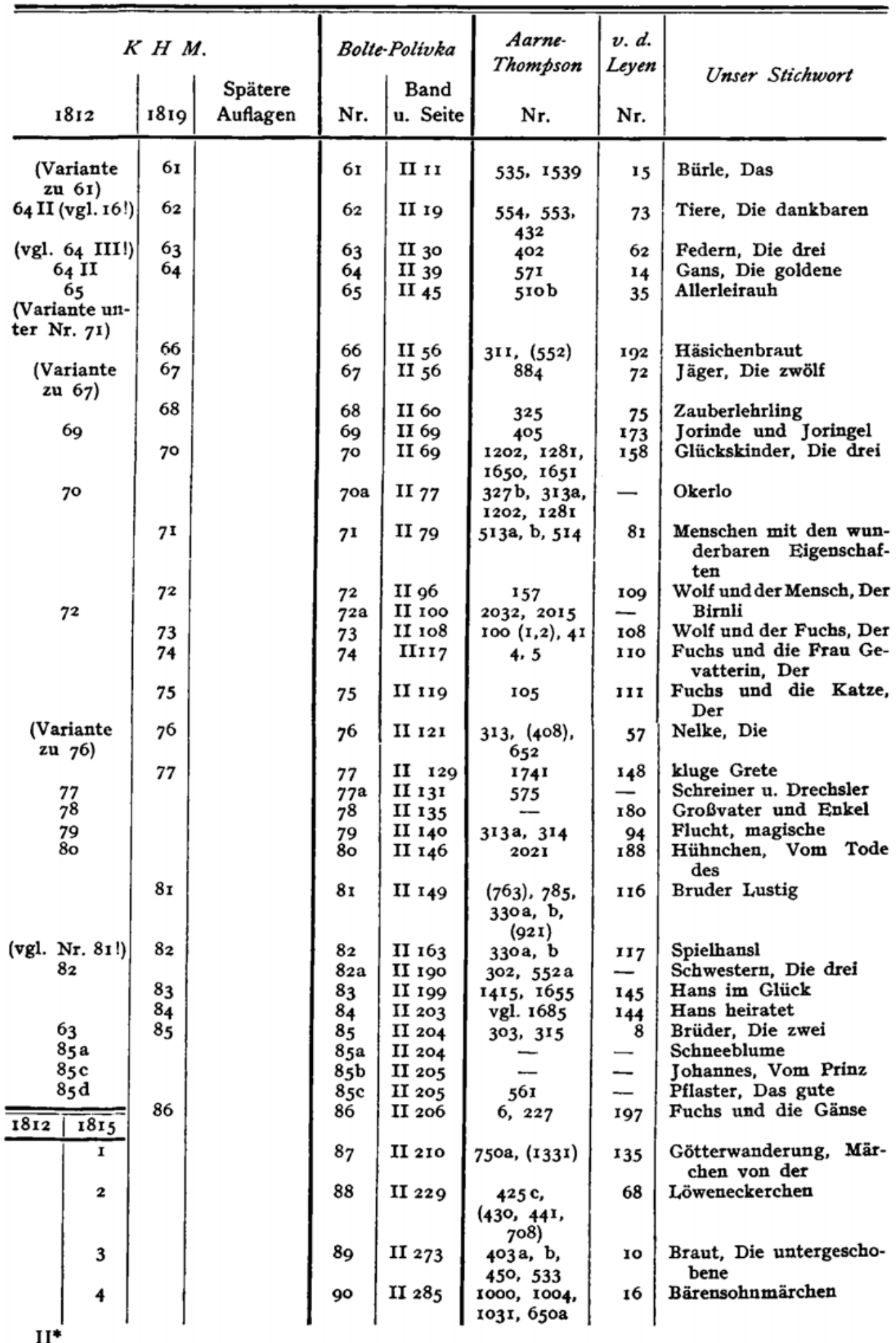




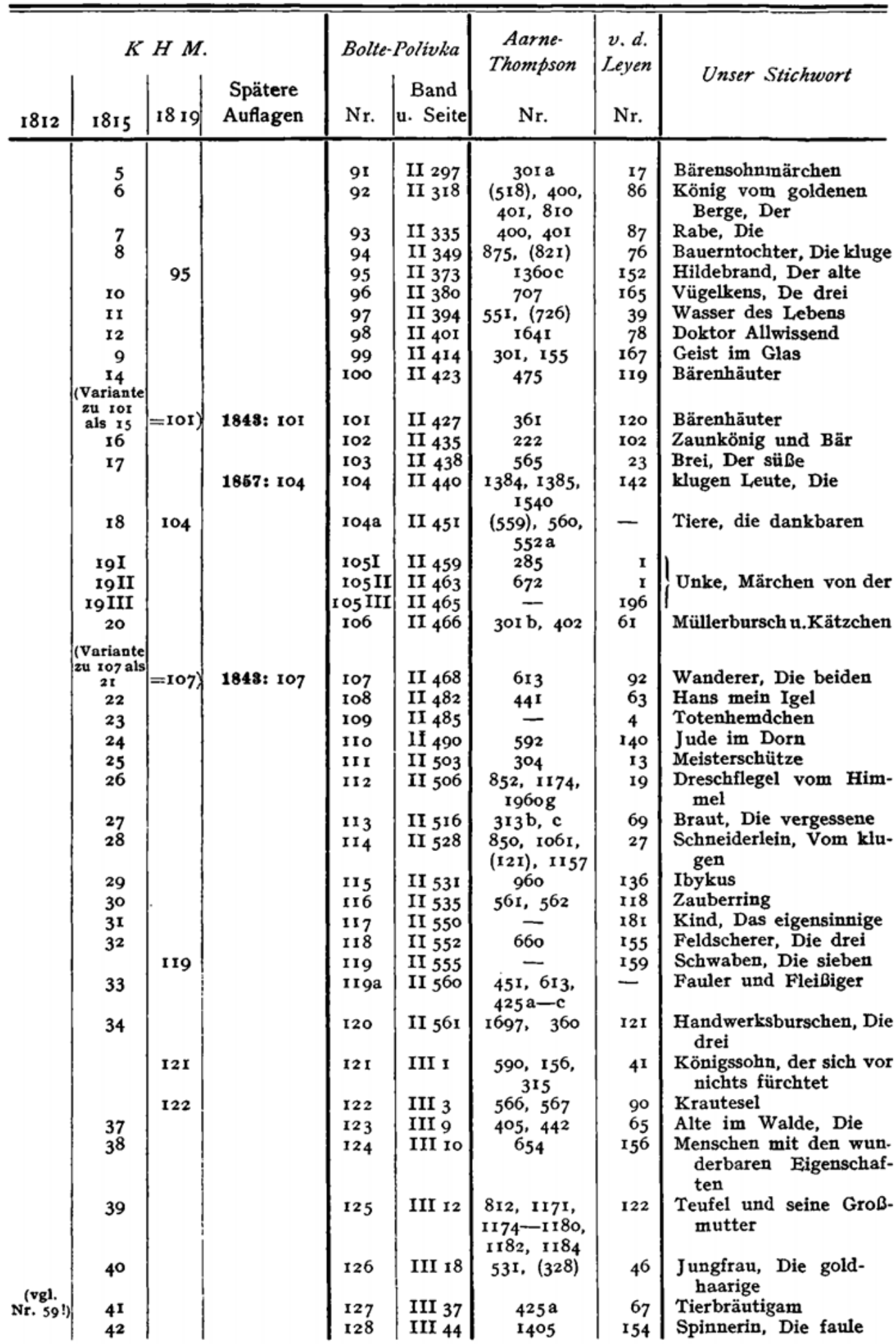




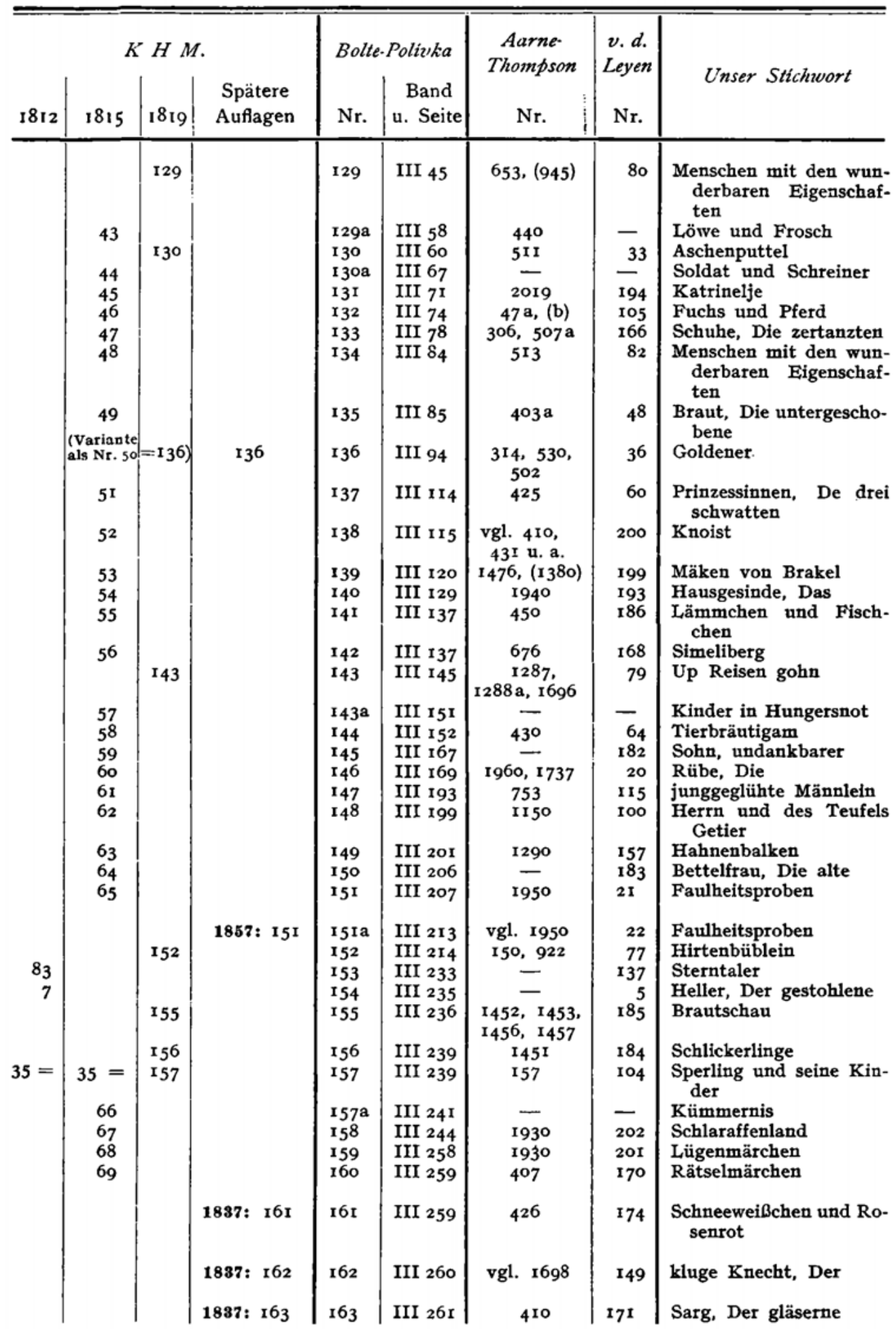




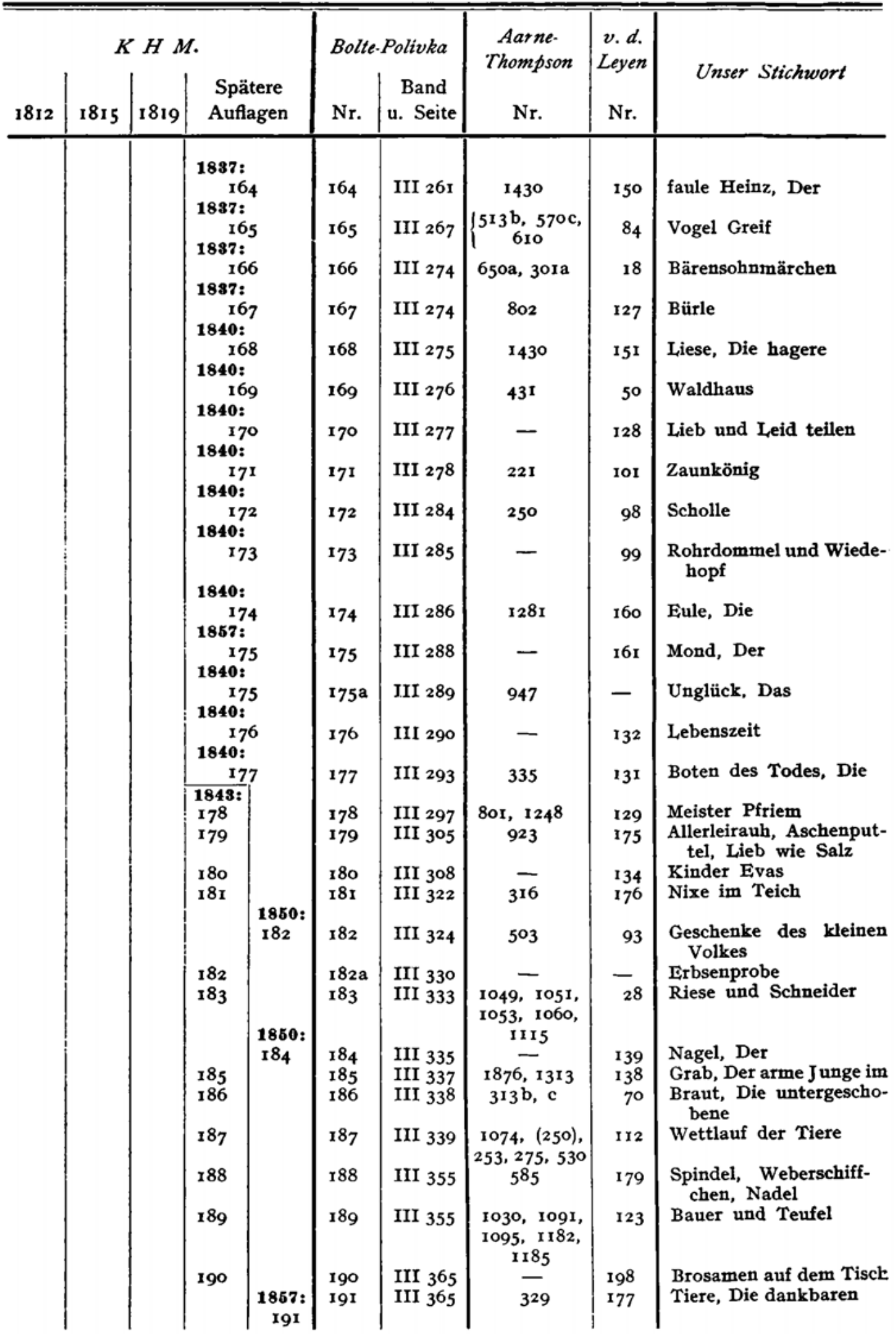




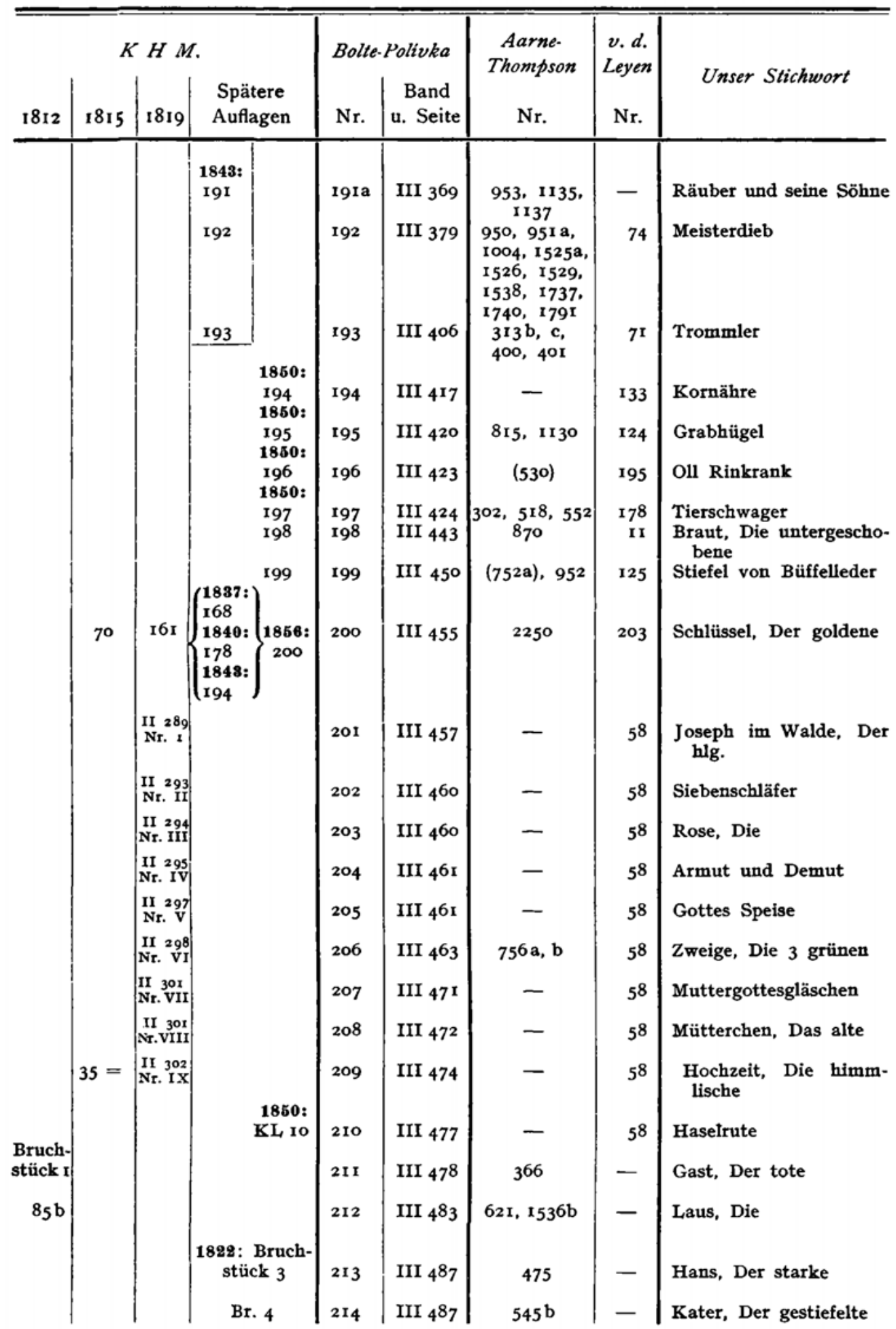




\begin{tabular}{|c|c|c|c|c|c|c|c|c|}
\hline 1812 & 1815 & 1819 & $\begin{array}{l}\text { Spätere } \\
\text { Auflagen }\end{array}$ & $\begin{array}{l}\text { Bolte } \\
\mathrm{Nr} .\end{array}$ & $\begin{array}{l}\text { Polivka } \\
\text { Band } \\
\text { u. Seite }\end{array}$ & $\begin{array}{c}\text { Aarne. } \\
\text { Thompson } \\
\text { Nr. }\end{array}$ & $\begin{array}{c}v . d . \\
\text { Leyen } \\
\text { Nr. }\end{array}$ & Unser Stichwort \\
\hline 84 & & & $\begin{array}{c}1856: \\
\text { S. 270 } \\
\text { Nach- } \\
\text { laB } \\
" \\
" \\
" \\
" \\
" \\
" \\
"\end{array}$ & $\begin{array}{l}215 \\
216 \\
217 \\
218 \\
219 \\
220 \\
221 \\
222 \\
223 \\
224 \\
225\end{array}$ & \begin{tabular}{|l} 
III 488 \\
III 489 \\
III 490 \\
III 5 II \\
III 531 \\
III 537 \\
III 538 \\
III $54^{2}$ \\
III 543 \\
III 556 \\
III $55^{8}$
\end{tabular} & $\begin{array}{c}410 \\
- \\
506 \mathrm{~b}, 507 \mathrm{~b} \\
880,888, \\
890 \\
307,(363) \\
326 \\
804 \\
200 \\
200,(1416) \\
513 \\
85\end{array}$ & $\begin{array}{l}- \\
- \\
= \\
= \\
- \\
- \\
-\end{array}$ & $\begin{array}{l}\text { Schwiegermutter, Die } \\
\text { böse } \\
\text { Volkslied } \\
\text { Toter, dankbarer } \\
\text { Frau, Die getreue } \\
\text { Prinzessin im Sarge } \\
\text { Fürchtenlernen } \\
\text { Peters Mutter } \\
\text { Feindschaft der Hunde } \\
\text { und Katzen } \\
\text { Hunde beriechen ein- } \\
\text { ander } \\
\text { Menschen mit den wun- } \\
\text { derbaren Eigenschaf- } \\
\text { ten } \\
\text { Mäuschen und Brat- } \\
\text { würstchen }\end{array}$ \\
\hline
\end{tabular}

